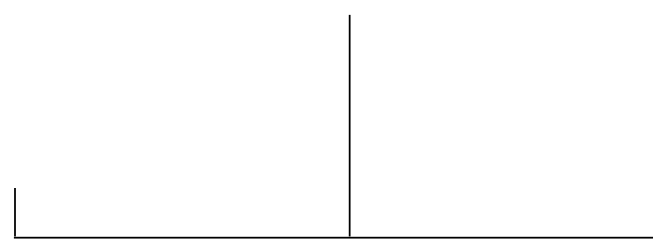

Rev. Latinoam. Psicopat. Fund., São Paulo, v. 15, n. 3, p. 540-548, setembro 2012

\title{
Sob a sombra do patológico: sujeito e verdade no adoecer*
}

Paulo José Carvalho da Silva

Este artigo analisa fontes da tradição da medicina da alma que tratam do adoecer. Inspirado em Georges Canguilhem, examina-se a noção de saúde e doença anterior às especializações modernas de modo a ressaltar que o adoecimento e as paixões que o acompanham são consequências da condição de vivente. Conclui-se que a antiga definição do humano como sujeito ao padecimento guarda semelhanças com o sujeito patológico concebido pela atual Psicopatologia Fundamental.

Palavras-chave: Adoecer, paixões, males da alma, sujeito, verdade

* Pesquisa realizada com apoio do Conselho Nacional de Desenvolvimento Científico e Tecnológico - CNPq (Brasília, DF, Br) (Bolsa de produtividade em Pesquisa). 
Ao defender que a patologia é sempre relacional, a tese de Georges Canguilhem (1904-1995), O normal e o patológico, lembra um fato que muitos preferem esquecer: "A ameaça da doença é um dos constituintes da saúde" (1999, p. 217). A própria noção de saúde é uma construção do discurso médico, algo como a projeção de um tipo ideal, portanto, imaginado. Essa imagem é formada como negativo da enfermidade, da decadência e da dor. Tal constatação leva o filósofo da ciência a concluir que é preciso, para se considerar normal, pressentir a sombra do patológico. Mas não sem antes levantar questões muito importantes para qualquer clínico: doença é risco, mas saúde é segurança? Há estabilidade permanente na fisiologia? E na vida psíquica?

Como bem destaca Vladimir Safatle (2011), as reflexões deste epistemólogo, cujo legado intelectual é fundamental para compreender o pensamento de Michel Foucault, Pierre Bourdieu e ainda de toda uma geração de marxistas e psicanalistas franceses, mostram, antes de mais nada, que se a doença faz o corpo falar, o sofrimento não fala por si mesmo. Ou seja, é preciso transformá-lo num discurso inteligível, o que depende de um dado olhar e, sobretudo, de uma escuta.

Segundo esta perspectiva, a escuta deve contemplar a singularidade de um adoecimento em particular, não apenas a doença, ao contrário da medicina do século XX que, sempre conforme o próprio Canguilhem (1999), trata os doentes não como sujeitos de sua doença, mas como objetos. 
A antiga tradição da medicina da alma pensava o adoecer de outra maneira. É certo que o aspecto mais discutido sobre a atitude tradicional a respeito da enfermidade e do sofrimento, segundo as práticas de tratamento dos males da alma embasados no cristianismo, é a valorização da condição de santidade, imitação do próprio sacrifício atribuído ao Cristo. Marvin R. O'Connell (1998) explica que, em especial, o catolicismo pós-tridentino julga o sofrimento como uma expiação do pecado, considerando, assim, sua aceitação paciente como exemplo edificante de fé e redenção. Com efeito, na literatura religiosa luso-brasileira, a enfermidade era sempre relacionada à queda do paraíso e, portanto, à condição faltante do homem enquanto criatura corrompida pelo pecado original (Nascimento, 2010).

Contudo, os discursos sobre o adoecer, produzidos dentro do espectro teórico da medicina da alma, não se resumem à ideia de castigo divino. Inclusive, o modo como se tratava as fronteiras entre o normal e o patológico apresenta mais semelhanças com o que hoje se pensa no âmbito da Psicopatologia Fundamental do que comumente se imagina. É o que trataremos neste artigo, a partir, em particular, da oratória do padre jesuíta Antônio Vieira, mas, acima de tudo, da tradição da medicina da alma.

\section{Mais natureza do que desgraça}

Canguilhem (2002) pensava as doenças como um preço a pagar pelo fato de estar vivo. Ou dito de outro modo: uma espécie de resgate pago pelos viventes que, sem ter pedido para nascer, devem aceitar o fato de que, necessariamente, desde o primeiro dia, rumam em direção a um fim imprevisível e inelutável.

Manoel Tosta Berlinck (2000) escreve que a Psicopatologia Fundamental considera que o corpo está sempre apto a ficar doente, sujeito a ser possuído por algo que vem de fora, como um vírus ou uma crise psíquica.

Uma definição do humano como espécie vulnerável ao padecimento é lugar-comum da medicina da alma. No Sermão de São Roque, proferido na Capela Real de Lisboa, em 1659, padre Antônio Vieira afirma: "Padecer alguma enfermidade, parece que é consequencia de ser mortal, e assim mais se deve chamar natureza que desgraça" (1659, vol. VIII, p.142).

Em tempos de guerras, fome e epidemias, não é de se estranhar que o discurso consolatório pregasse a aceitação da sombra constante da doença e da morte. Isso não significava, porém, a defesa unívoca e radical do abandono do corpo em nome da salvação da alma. Por exemplo, o fundador da ordem jesuítica, Inácio de Loyola (1491-1556), em carta ao jovem religioso enfermo Francesco 
D'Attino, datada de 7 de abril de 1554, afirma, sim, a importância de uma grande resignação e contentamento perante ao que Deus, tido como Pai e Médico, lhe confere como dom precioso, mas isso somente após terem se esgotado todos os meios razoáveis de tratamento.

De qualquer modo, a afirmação do risco de estar vivo era uma constante em todo tipo de aconselhamento psicológico. Martinho Lutero (1483-1546), em carta a Eberhard Brisger, reconhece que a doença que sofrem o amigo e sua esposa é perigosa, mas afirma que também o é a vida de modo geral. Ou ainda em carta ao seu próprio pai, escreve que nenhum momento da vida é seguro e nem poderia ser (1530).

A arte de bem viver e bem morrer produzida por reformados ou contrarreformados também insistia na noção de enfermidade como efeito do senhorio da morte na vida humana pós-paraíso. Mais do que isso, a dor é a lembrança no corpo da condição de desterrado da casa Paterna. O poeta inglês John Donne (1572-1631), em suas Meditações (1624), enfatiza a precariedade da saúde humana:

Estudamos a saúde, e deliberamos sobre nossas carnes, e bebemos e respiramos e nos exercitamos, além de talhar e polir cada pedra utilizada nessa construção; e assim a nossa saúde é um trabalho longo e regular, que em minutos um canhão abate a tudo, põe fim a tudo, demole tudo, uma enfermidade não prevista por toda a nossa diligência, inesperada por toda nossa curiosidade. (p. 11)

\section{Ainda pior que a doença, a solidão, mal da alma}

As consequências afetivo-psicológicas do adoecer não ficam de fora das considerações sobre a enfermidade. No mesmo Sermão de São Roque, com uma epidemia prestes a atingir Portugal, Vieira tece comentários sobre o contágio, quando o ar, suposto alimento e elemento da vida, torna-se a fonte de seu fim. Entretanto, o que ele considera o aspecto mais cruel da doença contagiosa atinge também a alma: a separação, o abandono e a segregação. Trata-se do movimento oposto ao esperado quando alguém estimado adoece, não apenas auxílio propriamente médico, mas, sobretudo, presença confortante no momento de dor. $\mathrm{Na}$ atmosfera pestilencial, o próprio doente, se de fato ama seus mais próximos, deve isolar-se.

A segunda razão ou miséria porque tenho pelo mais desgraçado de todos os males a peste, é, porque nas outras enfermidades o maior benefício que vos póde fazer quem vos ama, é estar comvosco: na peste a maior consolação que 
vos póde dar quem amaes é fugir de vós. Mal em que o dizer, estae comigo, é querer mal, e o dizer fugi de mim, é querer bem: Grande mal! Se a peste não fôra enfermidade mortal, só por isto matára. (Vieira, 1659, vol. VIII, p. 144)

John Donne é outro que medita sobre a solidão radical do enfermo:

Assim como a enfermidade é o maior dos sofrimentos, o maior pesar da enfermidade é a solidão: quando a infecção da doença impede aqueles que deveriam assisti-lo de se aproximarem; mesmo o médico raramente ousa vir. (...) Uma longa doença aborrece os amigos até não poder mais, mas uma doença pestilenta desvia-os desde o início. (Donne, 1624, p. 33)

De fato, conforme o extenso levantamento de Joël Coste (2007), a dura prova da peste era muito frequentemente vivida na solidão. A rede de solidariedade mobilizada em enfermidades comuns, isto é, os membros da família, os amigos mais próximos, os vizinhos ou os colegas, quando não igualmente atingidos pelo mal, afastavam-se dos doentes, muitas vezes confinados ao seu domicílio, exilados no interior ou abandonados em hospitais, quando disponíveis. Porém, Coste lembra que uma tradição literária, remontando ao relato da peste de Atenas escrito por Tucídides (460-400 a.C.) e reanimada pelo retrato da peste negra feito por Giovanni Boccacio (1313-1375), acentuou o que ele chama de fibra patética da imagem do pestífero, por frisar seu infortúnio ao ser abandonado por um irmão, pelo cônjuge ou, pior, pelos pais, como se esses não mais o reconhecessem como filho.

Impossível não presumir que essa tal fibra patética fala de um "a mais", o qual desconhece os limites da experiência propriamente física da doença e encorpa o seu sofrimento, incrementa seu pesar, mal da alma.

Havia, na primeira modernidade, aqueles que pregavam o combate às paixões que acompanham o adoecer. Um bom exemplo é a arte de bem morrer de Roberto Bellarmino (1621) que inclui a sutileza de tratar os perigos em torno do horror, do torpor, da tristeza e do tédio supostos a assolar o enfermo. Já Charles Drelincourt (1663) lembra, de Genebra, que seriam necessários vários volumes para descrever todas as enfermidades que minam o corpo, mas ele se preocupa particularmente com as "tristezas profundas" e "angústias mortais" que afligem o espírito humano sujeito ao adoecimento (p. 460).

Tudo isso faz lembrar as considerações de Canguilhem (2002) segundo as quais as doenças humanas não são apenas limitações de poder físico de uma pessoa, são dramas de sua história, de sua existência. É justamente o oposto da orientação de uma dada medicina positivista, expressa modelarmente na afirmação do cirurgião francês René Leriche (1859) de que, na doença, o que menos importa é o homem. 
No Sermão do Evangelista São Lucas, Vieira afirma que: “A primeira coisa”, diz Aristóteles, "que se ha-de considerar no enfermo, é o sujeito, mas não quem é, mas qual" (Vieira, s.d./1951, vol. VIII, p. 431). Vieira faz uma advertência aos médicos ambiciosos que orientam sua prática pela distinção de nobreza do enfermo, preferindo tratar de ricos e nobres, adulando-os com o intuito de ganhar mais dinheiro. É nesse sentido que ele, atribuindo a frase ao filósofo Aristóteles, precisa que por sujeito entende-se não quem, mas que tipo de particularidade apresenta o enfermo em questão, como mostra a seguinte passagem:

De sorte que a consideração do sujeito há-de examinar, se é robusto ou delicado, se de muitas ou poucas forças, se d'este ou d'aquele exercício; mas n'esta distincção, e na do temperamento não há-de entrar a da qualidade e dignidade da pessoa, sob pena de ficar bem lisonjeado o doente, e mal curado. (p. 432)

Inclusive, Vieira lembra que o médico deve ser como a própria enfermidade e não fazer diferença de posição social, afinal, são os humanos feitos da mesma matéria:

O medico não cura a púrpura, nem a coroa, senão o homem despido, e o corpo que em todos é do mesmo barro; e onde o medico quis fazer distincção de barro a barro, alli se perdeu. (...) Mas como os palacios dos reis, aonde os medicos não são chamados senão por necessidade, assim como têm portas sempre abertas à adulação e lisonja, assim ellas por si mesmas se fecham à verdade; muito valor ha mister a do medico que houver de curar a um rei, como a um homem. (p. 433)

Para além da crítica à cobiça dos médicos, Vieira enfatiza duas orientações fundamentais na arte da cura, que ultrapassam o contexto da medicina de então. Em primeiro lugar, ele deixa claro que é o sujeito e não a enfermidade o que deve ser tratado. E, não menos importante: o tratamento deve, a despeito de outros desejos, perseguir a verdade.

No campo da pesquisa em Psicopatologia Fundamental, Lazlo Antônio Ávila (2004) tem defendido que a doença é uma coisa pessoal, o que exige tratar o indivíduo enquanto sujeito ativo de seu próprio adoecer, sabendo que, independentemente da origem de seu mal, o doente dá um curso pessoal ao seu enfermar.

Para tratar o enfermo enquanto sujeito e orientar esse tratamento conforme a verdade, é preciso, antes de mais nada, fazer o paciente falar sobre sua doença, digamos; associar sobre o seu drama de estar vivo e, portanto, de sua existência solitária face à sombra de sua própria finitude. Enfim, segundo Jacques Lacan (1966), foi exatamente isso que Freud fez ao inventar a psicanálise: sob o nome de inconsciente, soube deixar falar a verdade. 


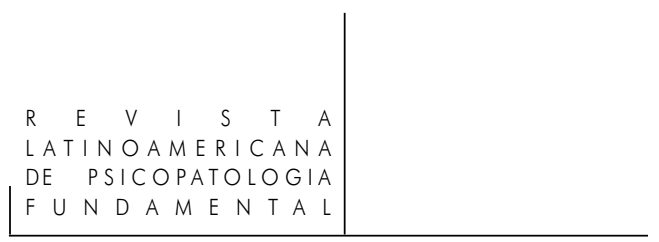

\section{Referências}

Ávila, L.A. O еи е o corpo. São Paulo: Escuta, 2004.

Bellarmino, R. L'arte di ben morire. Casale Monferrato: Edizzioni Piemme, 1998.

Berlinck, M.T. Psicopatologia Fundamental. São Paulo: Escuta, 2000.

Canguilhem, G. Le normal et le pathologique. Paris: Quadrige/Presses Universitaire de France, 1999.

Canguilhem, G. Écrits sur la médecine. Paris: Éditions du Seuil, 2002.

Coste, J. Représentations et comportements en temps d'épidémie dans la littérature imprimée de peste (1490-1725). Contribuition à l'histoire culturelle de la peste en France à l'époque moderne. Paris: Honoré Champion, 2007.

Donne, J. (1624). Meditações. Edição bilíngue. Traduzido por F. Cyrino. São Paulo: Landmark, 2007.

Drelincourt C. Les consolations de l'âme fidele, contre les frayeurs de la mort. Avec les dispositions \& les preparations necessaires pour bien mourir. Genève: Pour I. Ant. \& Samuel De Tournes, 1663.

LaCAN, J. La science et la vérité. In: Écrits . Paris: Éditions du Seuil, 1966. p. 855-77.

Loyola, I. Écrits. Trad. e org. por M. Giuliani, P-A. Fabre, L. Giard. Paris: Desclée de Brouwer, 1991.

LuTERo, M. Vom getrosten Leben: Martin Luthers Trost-briefe. G. Blail (org.). Stuttgart: Steinkopf, 1982.

Nascimento, F.A.F. A ideia de enfermidade em um sermão de Padre Antonio Vieira: uma contribuição aos estudos sobre as ideias psicológicas no Brasil. 2010. 122p. Dissertação (Mestrado em História da Ciência), Pontifícia Universidade Católica de São Paulo - PUC-SP, 2010.

O'Connell, M.R. The Roman Catholic tradition since 1545. In: Numbers, R.L.; Amundsen, D.W. (Org.). Caring and curing. Health and medicine in the western religious traditions. Baltimore/London: The Johns Hopkins University Press, 1998.

Safatle, V. O que é uma normatividade vital? Saúde e doença a partir de Georges Canguilhem. Scientia Studia, v. 9, p. 11-27, 2011.

VIEIRA, A. Sermões. Vol. VIII. Porto: Lello \& Irmão, 1951. 


\section{Resumos}

(Beneath the Shadow of the Pathological: Subject and Truth in Getting Sick)

This article analyzes primary sources from the tradition of "medicine of the soul," which deals with the experience of getting sick. Inspired by Georges Canguilhem, the notions of health and disease that were available before the development of modern specializations are examined in order to show that falling ill and the emotions related to this process are actually consequences of being alive. The author concludes that the ancient definition of human as vulnerable to suffering has close similarities with the pathological subject, which is conceived in today's field of fundamental psychopathology.

Key words: Getting sick, passions, illness of the soul, subject, truth

(Sous l'ombre du pathologique: sujet et vérité dans le devenir malade)

Cet article analyse des sources de la médecine de l'âme qui traitent de l'expérience de la maladie. Inspiré par Georges Canguilhem, on examine les notions de santé et de maladie antérieures aux spécialisations modernes d'une façon a montrer qu'être malade et les passions de l'âme qui s'en suivent ne sont que des conséquences d'être vivant. On conclue que l'ancienne définition de l'homme comme sujet aux souffrances garde des similarités importantes avec le sujet pathologique de la Psychopathologie fondamentale.

Mots clés: Devenir malade, passions de l'âme, maux de l'âme, sujet, vérité

(Bajo la sombra de lo patológico: sujeto y verdad en el adolecer)

Este artículo analiza las fuentes de la tradición de la medicina del alma que tratan del adolecer. Inspirado en Georges Canguilhem, se examina la noción de salud y de enfermedad anterior a las especialidades modernas de manera a resaltar que el adolecer y las pasiones que lo acompañan son consecuencias de la condición de estar vivo. Se concluye que la definición antigua de lo humano como sujeto del padecimiento guarda semejanzas con el sujeto patológico concebido por la actual Sicopatología Fundamental.

Palabras clave: adolecer, pasiones, males del alma, sujeto, verdad

(Unter dem Schatten der Pathologie: Subjekt und Wahrheit im erkranken)

Dieser Artikel analysiert Quellen der Medizin für die Seele, die die Erfahrung der Krankheit behandeln. Inspiriert von Georges Canguilhem werden die Vorstellungen von Gesundheit und Krankheit in der Zeit vor den modernen Spezialisierungen untersucht, um zu zeigen, dass Erkrankung und die sich daraus ergebenden 
Leidenschaften der Seele Folge des lebendigen Zustands sind. Es erschließt sich, dass die alte Definition über den Mensch als zum Leiden verwundbares Wesen Ähnlichkeiten mit dem pathologischen Subjekt der aktuellen Fundamentalpsychopathologie aufweist.

Schlüsselwörter: Erkranken, Leidenschaften, Leiden der Seele, Subjekt, Wahrheit

Citação/Citation: SiLVA, P.J.C. DA. Sob a sombra do patológico: sujeito e verdade no adoecer. Revista Latinoamericana de Psicopatologia Fundamental, São Paulo, v. 15, n. 3, p. 566-574, set.2012.

Editor do artigo/Editor: Prof. Dr. Paulo José Carvalho da Silva

Recebido/Received: 2.5.2012 / 5.2.2012 Aceito/Accepted: 6.6.2012 / 6.6.2012

Copyright: () 2009 Associação Universitária de Pesquisa em Psicopatologia Fundamental/ University Association for Research in Fundamental Psychopathology. Este é um artigo de livre acesso, que permite uso irrestrito, distribuição e reprodução em qualquer meio, desde que o autor e a fonte sejam citados / This is an open-access article, which permits unrestricted use, distribution, and reproduction in any medium, provided the original author and source are credited.

Financiamento/Funding: Esta pesquisa é financiada pelo Conselho Nacional de Desenvolvimento Científico e Tecnológico - CNPq/This research is funded by the National Counsel of Technological and Scientific Development - CNPq

Conflito de interesses/Conflict of interest: $\mathrm{O}$ autor declara que não há conflito de interesses / The author declares that has no conflict of interest.

\section{Paulo José Carvalho da Silva}

Psicólogo, psicanalista, mestre em História da Ciência pela Pontifícia Universidade Católica de São Paulo - PUC-SP (São Paulo, SP, Br); doutor em Psicologia pela Universidade de São Paulo - USP (São Paulo, SP, Br); professor doutor da Faculdade de Psicologia da PUC-SP (São Paulo, SP, Br); membro da Associação Universitária de Pesquisa em Psicopatologia Fundamental (São Paulo, SP, Br).

Rua Monte Alegre, 984

05015-901 São Paulo, SP, Brasil

Fone: (11) 9248-9202

e-mail: paulojcs@hotmail.com 